Article

\title{
Enthalpies of Adduct Formation between Boron Trifluoride and Selected Organic Bases in Solution: Toward an Accurate Theoretical Entry to Lewis Basicity
}

\author{
Jean-François Gal ${ }^{1, *(\mathbb{D})}$, Pierre-Charles Maria ${ }^{1}$ (D), Manuel Yáñez ${ }^{2}$ and Otilia Mó ${ }^{2}$ (i) \\ 1 Institut de Chimie de Nice, UMR 7272, Université Côte d'Azur, Parc Valrose, 06108 Nice, France; \\ Pierre-Charles.MARIA@univ-cotedazur.fr \\ 2 Departamento de Química (Módulo 13, Facultad de Ciencias) and Institute of Advanced Chemical \\ Sciences (IadChem), Campus de Excelencia UAM-CSIC, Cantoblanco, Universidad Autónoma de Madrid, \\ 28049 Madrid, Spain; manuel.yanez@uam.es (M.Y.); otilia.mo@uam.es (O.M.) \\ * Correspondence: Jean-Francois.GAL@univ-cotedazur.fr
}

\section{check for} updates

Citation: Gal, J.-F.; Maria, P.-C.; Yáñez, M.; Mó, O. Enthalpies of Adduct Formation between Boron Trifluoride and Selected Organic Bases in Solution: Toward an Accurate Theoretical Entry to Lewis Basicity. Molecules 2021, 26, 6659. https: / / doi.org/10.3390/ molecules26216659

Academic Editors: Federico Totti and Anan Yaghmur

Received: 1 October 2021

Accepted: 1 November 2021

Published: 4 November 2021

Publisher's Note: MDPI stays neutral with regard to jurisdictional claims in published maps and institutional affiliations.

Copyright: (c) 2021 by the authors. Licensee MDPI, Basel, Switzerland. This article is an open access article distributed under the terms and conditions of the Creative Commons Attribution (CC BY) license (https:/ / creativecommons.org/licenses/by/ $4.0 /)$.

\begin{abstract}
The Lewis basicity of selected organic bases, modeled by the enthalpies of adduct formation between gaseous $\mathrm{BF}_{3}$ and bases in dichloromethane (DCM) solution, is critically examined. Although experimental enthalpies for a large number of molecules have been reported in the literature, it may be desirable to estimate missing or uncertain data for important Lewis bases. We decided to use high-level ab initio procedures, combined with a polarized continuum solvation model, in which the solvated species were the clusters formed by specific hydrogen bonding of DCM with the Lewis base and the Lewis base $/ \mathrm{BF}_{3}$ adduct. This mode of interaction with DCM corresponds to a specific solvation model (SSM). The results essentially showed that the enthalpy of $\mathrm{BF}_{3}$ adduct formation in DCM solution was clearly influenced by specific interactions, with DCM acting as hydrogen-bonding donor (HBD) molecule in two ways: base/DCM and adduct/DCM, confirming that specific solvation is an important contribution to experimentally determined Lewis basicity scales. This analysis allowed us to conclude that there are reasons to suspect some gas-phase values to be in error by more than the stated experimental uncertainty. Some experimental values in DCM solution that were uncertain for identified reasons could be complemented by the computed values.
\end{abstract}

Keywords: $\mathrm{BF}_{3}$ enthalpies; Lewis basicity; specific solvation; high-level ab initio calculations; dichloromethane; boron trifluoride

\section{Introduction}

The quantitative characterization of the Lewis basicity of a molecule or a functional group in a complex system is frequently a prerequisite for understanding the Lewis acid/base interactions, which are pivotal in many fundamental and applied fields. The IUPAC definition of Lewis basicity as the "thermodynamic tendency of a substance to act as a Lewis base" is fundamentally correct, but, for practical realization, it is primarily measured either as Gibbs energies or enthalpies of adduct formation relative to a standard Lewis acid, in the gas phase or in an inert (or assumed so) solvent [1-9].

Basicity is a multidimensional property [10-12], but characterization of an interaction with a multiparametric model is rather complex and requires an extended set of carefully chosen data.

For these reasons, the use of unidimensional scales (using a single reference Lewis acid) is often preferred, for example, by looking at a simple linear regression. There are several critically evaluated Lewis basicity scales, covering a respectable range of bases [5]. These scales deal with the most useful interactions, including adduct formation with classical Lewis acids (in particular $\mathrm{SbCl}_{5}$ and $\mathrm{BF}_{3}$ ), hydrogen bonding, halogen bonding, and gasphase metal cation affinities. In fact, one of the most cited Lewis basicity scales is the 
so-called "Donor Number" (DN) developed by Viktor Gutmann and his followers [13,14]. The DN was initially defined as the calorimetric measurement of the enthalpy of adduct formation between $\mathrm{SbCl}_{5}$ and a Lewis base (LB) both dissolved in 1,2-dichloroethane (DCE).

$$
\mathrm{SbCl}_{5(\mathrm{DCE})}+\mathrm{LB}_{(\mathrm{DCE})} \rightarrow\left[\mathrm{LB}-\mathrm{SbCl}_{5}\right]_{(\mathrm{DCE})}
$$

Despite various drawbacks, in particular experimental problems [5], the use of secondary non-calorimetric measurements to expand the scale, and traceability of the data [15], the DN scale is still cited as a fundamental reference in state-of-the-art research on materials [16-24], to cite only a few recent works.

Using a similar calorimetric definition, two of us established a Lewis basicity scale founded on the enthalpies of reaction between gaseous $\mathrm{BF}_{3}$ and a Lewis base in dichloromethane (DCM) solution $[5,25]$ :

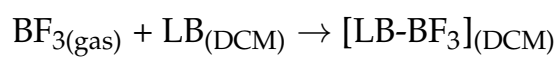

Measurements were also carried out in nitrobenzene (NB) solution:

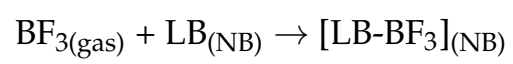

This $\triangle \mathrm{HBF}_{3}$ scale $\left(\mathrm{BF}_{3} \mathrm{~A}\right.$ in [5] where $\mathrm{A}$ was used by analogy with $\mathrm{PA}$, the proton affinity measured by an enthalpy) presents several advantages over DN, particularly with regard to the range of enthalpies covered via a single technique, the wide structural variation among the LBs, and its rigorous traceability from the same laboratory, including repeatability tests of calorimetric measurements [26].

In fact, the $\mathrm{DN}$ and $\triangle \mathrm{HBF}_{3}$ scales are strongly correlated [5,25], within the range of $\mathrm{O}$ and N-bases for which data are available.

Owing to the need for data on the Lewis basicity of molecules not experimentally characterized [27], several attempts were recently made to estimate either $\mathrm{SbCl}_{5}$ or $\mathrm{BF}_{3}$ enthalpies of adduct formation by quantum chemistry methods; see, for example, [22,28-30].

We also contributed to the evaluation of high-level theoretical methods for calculating the enthalpies for reactions (1) and (2) [31].

There are also data corresponding to $\mathrm{BF}_{3}$ enthalpies experimentally determined in the gas phase:

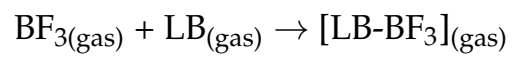

In this work, we investigate the best available ab initio methods compatible with the size of the adducts to calculate $\mathrm{BF}_{3}$ enthalpies of adduct formation, i.e., reactions (2) and (3). In the case of reactions (2), we chose a series of representative Lewis bases covering the maximum span of the $\triangle \mathrm{HBF}_{3}$ scale. Examination of reaction (3) was limited to the data available in the literature.

The energetics associated with the interaction of the different bases under study with $\mathrm{BF}_{3}$ were investigated using a $\mathrm{G}^{*}$ ab initio method that is described in detail in the Section 3.2. Our aim was to determine how close we could come to the experimental enthalpies of adduct formation, both in the gas phase and in solution. For measurements in DCM solution using $\triangle \mathrm{HBF}_{3}$, for which there is a large choice of experimental data [5], the examination of models of solvent effects was believed to be essential.

From the definitions of $\mathrm{DN}$ and $\triangle \mathrm{HBF}_{3}$ following reactions (1) and (2) respectively, the two Lewis basicity scales correspond to Lewis bases and their adducts as solutes diluted in a given solvent (solute scales). This point is often overlooked, and these scales are very frequently treated as solvent scales, leading one to believe that interactions between solvent and solute molecules are only considered in terms of Lewis acid/Lewis base binding [32-34]. This approximation may be an acceptable approximation for weakly associated liquids used as solvents, but is certainly not valid for self-associated liquids [35]. 


\section{Results and Discussion}

\subsection{Gas Phase Enthalpies}

As a prerequisite for potential comparisons between theoretical and experimental enthalpies of $\mathrm{BF}_{3}$ adduct formation with bases and adducts in solution (reaction 2), an exploratory analysis of gas-phase data was conducted on seven selected Lewis bases. As the reaction of adduct formation with $\mathrm{BF}_{3}$ is always exothermic (negative values), we systematically list and discuss $-\Delta H$ values for convenience. The enthalpies were calculated at a slightly modified G4 level, described in the Section 3.2, and we label this procedure $\mathrm{G} 4 *$, to distinguish it from the standard G4 method. The experimental and calculated enthalpies of reaction (3) at the G4* level are listed in Table 1. The B3LYP/aug-cc-pVTZ optimized geometries of the $\mathrm{BF}_{3}$ complexes in the gas phase are given in Table $\mathrm{S} 4$ of the Supplementary Materials.

Table 1. Gas-phase enthalpies $(-\Delta H)$ of adduct formation with Lewis bases; values in $\mathrm{kJ} \cdot \mathrm{mol}^{-1}$ at $298 \mathrm{~K}$ unless otherwise noted.

\begin{tabular}{|c|c|c|c|}
\hline Lewis Base & G4 $4^{*}$-Calculated ${ }^{a}$ & Experimental & $\Delta($ Calc. - Exp. $)$ \\
\hline Trimethylamine & 126.4 & $111.3 \pm 8.4^{b}[36-38]$ & 15.1 \\
\hline Dimethyl ether & 62.4 & $57.1 \pm 0.8[39]$ & 5.3 \\
\hline Tetrahydrofuran & 72.5 & $70.3 \pm 0.8[40]$ & 2.2 \\
\hline Tetrahydropyran & 69.0 & $64.5 \pm 0.8[40]$ & 4.5 \\
\hline Ethyl acetate & 55.9 & $53.6 \pm 2.9[41]$ & 2.3 \\
\hline Trimethylphosphine & 66.1 & $79.1[42,43]$ & -13.0 \\
\hline Tetrahydrothiophene & 37.9 & $21.8 \pm 1.7[44]$ & 16.1 \\
\hline
\end{tabular}

${ }^{a}$ see text and Section $3.2 ;^{b}$ at $273 \mathrm{~K}$.

The calculated values were in fair agreement for the O-bases, but rather significant deviations were observed for the N-, S- and P-bases. It should be noted that most of these experimental enthalpies were obtained via tensimetric measurements of the dissociation of the gas-phase adducts at different temperatures, which are subject to systematic errors, in particular for the early studies [45].

The gas-phase trimethylamine experimental enthalpy listed in Table 1 was estimated from a thermochemical cycle involving conjectured quantities for both the enthalpy of formation of the solid trimethylamine/boron trifluoride adduct $\left(42 \pm 2 \mathrm{kcal} \cdot \mathrm{mol}^{-1}\right)$ and for its enthalpy of sublimation $\left(15 \mathrm{kcal} \cdot \mathrm{mol}^{-1}\right)$ [38]; a higher reported value $\left(68.9 \mathrm{~kJ} \cdot \mathrm{mol}^{-1}\right.$ at $393 \mathrm{~K}$ ) [46] would worsen the deviation between calculated and experimental values. Therefore, the often-quoted value reported in Table 1 appears to be a rough estimate, and the calculated value is probably a better approximation of the true one. As a matter of fact, the G4 calculated proton affinity (PA) of trimethylamine $\left(950.4 \mathrm{~kJ} \cdot \mathrm{mol}^{-1}\right)$ was in very good agreement with the experimental value $\left(948.9 \mathrm{~kJ} \cdot \mathrm{mol}^{-1}\right)$ [47], showing that the G4 method reproduced very well the enthalpies of both the neutral trimethylamine and its protonated form, and it is not likely that it overestimated the stability of the trimethylamine $/ \mathrm{BF}_{3}$ adduct. The good agreement between the experimental PAs and the G4-calculated values was also observed for all the other Lewis bases included in this study, as shown in Table S3 of the Supplementary Materials.

For the tetrahydrothiophene/ $\mathrm{BF}_{3}$ adduct [44], the authors reported some decomposition during the vaporization of the solid adduct. In this case, the G4 calculated PA $\left(848.7 \mathrm{~kJ} \cdot \mathrm{mol}^{-1}\right)$ was again in excellent agreement with the experimental value $\left(849.1 \mathrm{~kJ} \cdot \mathrm{mol}^{-1}\right)$ [47], which leads us to believe that the theoretical estimate for the enthalpy of formation of the tetrahydrothiophene $/ \mathrm{BF}_{3}$ adduct is probably the closest to the correct value. A similar decomposition problem was reported for the trimethyl phosphine $/ \mathrm{BF}_{3}$ adduct [43], for which the theoretical estimate, as was the case for trimethylamine, is significantly larger than the experimental value, whose cited source of data [48] is difficult to trace. 
To summarize, there are reasons to suspect some gas-phase values to be in error by more than the stated experimental uncertainty.

It is also interesting to mention that in principle one could naively think that the basicity of the compounds included in our analysis with respect to $\mathrm{BF}_{3}$ should follow the same trends as their intrinsic (gas-phase) Brønsted basicity, i.e., the trend exhibited by the gas-phase proton affinities. This was indeed the case when dimethyl ether was compared with tetrahydrofuran and tetrahydropyran. Dimethyl ether exhibited a $\mathrm{BF}_{3}$ enthalpy smaller than tetrahydrofuran and tetrahydropyran, as was the case for their intrinsic Brønsted basicities (PAs): $792.0 \mathrm{~kJ} \cdot \mathrm{mol}^{-1}$ for dimethyl ether and 822.1 and $822.8 \mathrm{~kJ} \cdot \mathrm{mol}^{-1}$ [47], respectively, for tetrahydrofuran and tetrahydropyran. This result seems to be consistent, as shown in Figure 1, with the electron densities at the corresponding B-O bond critical points (BCPs), being lower for dimethyl ether $/ \mathrm{BF}_{3}$ complex than for the complexes involving tetrahydrofuran and tetrahydropyran. In addition, consistently, the Wiberg bond order obtained in the framework of the NBO approach for the B-O interaction was also smaller for the dimethyl ether $/ \mathrm{BF}_{3}$ complex $(0.377)$ than for the tetrahydrofuran $/ \mathrm{BF}_{3}$ and tetrahydropyran $/ \mathrm{BF}_{3}$ ones ( 0.386 and 0.398 , respectively). However, when considering the couple tetrahydrofuran and tetrahydropyran, we observed that whereas their PAs were practically equal, as mentioned above, the $\mathrm{BF}_{3}$ affinity of tetrahydrofuran was clearly larger (both the theoretical estimates and the experimental measurements) than that of tetrahydropyran. More significant are the changes when looking at the values associated with ethyl acetate. Both the calculated and the experimental $\mathrm{BF}_{3}$ affinities for ethyl acetate were the lowest of the four oxygen bases included in Table 1, whereas its proton affinity $\left(835.7 \mathrm{~kJ} \cdot \mathrm{mol}^{-1}\right)$ was the largest of the series. These results are in line with those reported by A. Rauk et al. [49] based on MP2 ab initio calculations.
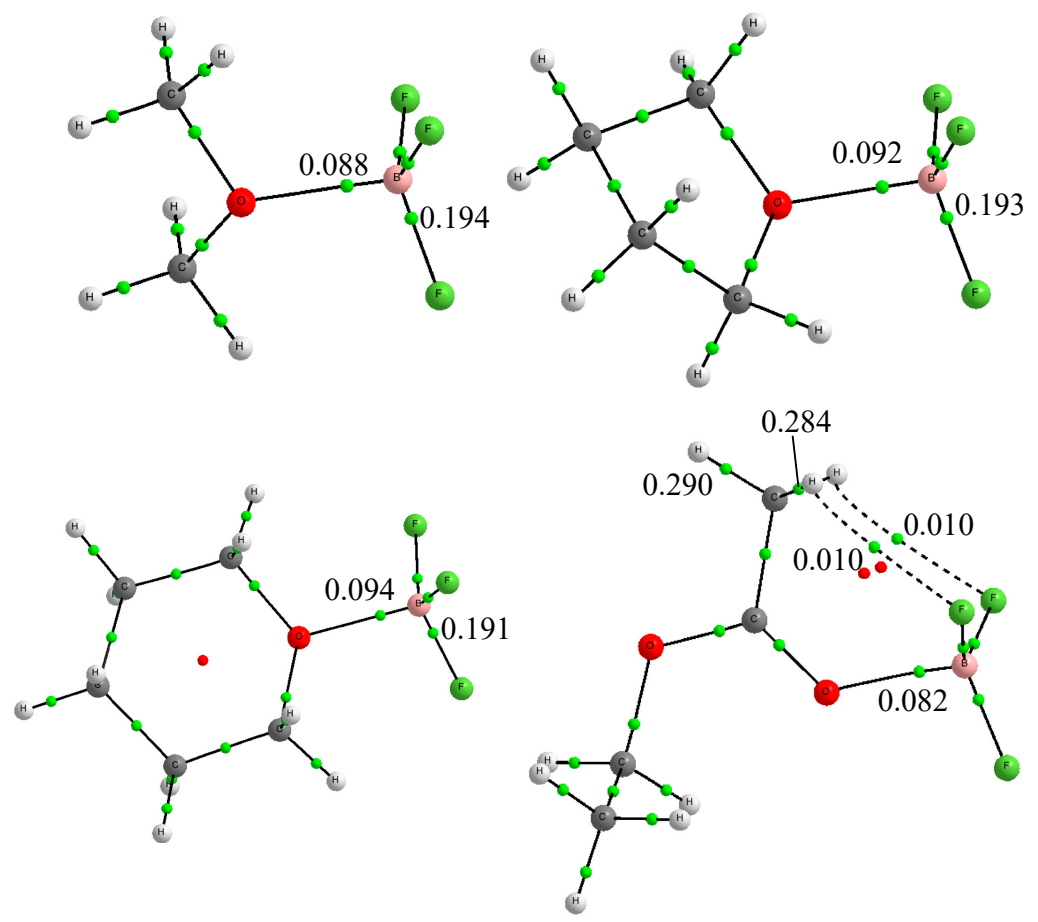

Figure 1. Molecular graphs for the complexes between dimethyl ether, tetrahydrofuran, tetrahydropyran and ethyl acetate with $\mathrm{BF}_{3}$. The green dots show the positions of the bond critical points, whose electron density in a.u. is indicated for relevant cases.

It must be ratified, then, that no correlation should be expected between $\mathrm{BF}_{3}$ interaction enthalpies and proton affinities. As a matter of fact, protonation is a very different process in which the attachment of a proton to the basic site of the base implies a huge charge transfer from the base, with a concomitant strong polarization of its charge density, to the 
incoming proton, resulting in the formation of a new covalent bond between the basic site and the proton. On top of that, another important difference between the protonation process and the formation of $\mathrm{BF}_{3}$ complexes is the possibility, in the last case, of additional non-covalent interactions between the fluorine atoms of $\mathrm{BF}_{3}$ and other atoms of the base, which are not possible in protonation processes. This was quite evident when looking at the molecular graph of the ethyl acetate $/ \mathrm{BF}_{3}$ complex, which shows the formation of $\mathrm{C}-\mathrm{H} \cdots \mathrm{F}$ hydrogen bonds between the $\mathrm{C}-\mathrm{H}$ bonds of the base and the $\mathrm{BF}_{3}$ fluorine atoms. The formation of these hydrogen bonds was also corroborated by the NBO analysis, which shows a non-negligible population of the corresponding $\mathrm{C}-\mathrm{H}$ antibonding orbitals, resulting in a lengthening of $0.006 \AA(1 \AA=100 \mathrm{pm})$ in the two C-H bonds involved, and a decrease in the electron density at the C-H BCP (see Figure 1).

\subsection{Enthalpies in Solution}

From the very large $\Delta \mathrm{HBF}_{3}$ data set measured in DCM [5,10,25,31], we selected a series of Lewis bases which partly overlap the experimental gas-phase enthalpies of reaction (3) and cover the largest possible range of Lewis basicities, with a wide variation among functional groups. The selection included quinuclidine, one of the strongest bases $\left(150 \mathrm{~kJ} \cdot \mathrm{mol}^{-1}\right)$ in this solute scale, and nitrobenzene (acting as a Lewis base, $36 \mathrm{~kJ} \cdot \mathrm{mol}^{-1}$ ) as the weakest.

Some $\mathrm{BF}_{3}$ enthalpies were also measured in nitrobenzene as solvent [25], not only to check the medium effect, but also due to solubility problems or because secondary reactions between DCM and some bases or their adducts plagued calorimetric measurements. The experimental data are listed in Table 2. The listed uncertainties, defined as the $95 \%$ confidence interval, correspond to the short-term repeatability. Systematic errors, discussed in detail in Section 3, may add approximately 1 to $2 \mathrm{~kJ} \cdot \mathrm{mol}^{-1}$ to the listed uncertainties.

Several experimental data were unpublished, so the experimental method [26] is briefly recalled in the Section 3.

For a series of 12 well-behaved Lewis bases, a linear least square regression between the $\mathrm{BF}_{3}$ enthalpies in the two solvents (dichloromethane and nitrobenzene) leads to Equation (4) (coefficient of determination $R^{2}=0.9940$; units $\mathrm{kJ} \cdot \mathrm{mol}^{-1}$ ) [25].

$$
-\Delta H_{(\mathrm{DCM} \text { solution })}=0.958\left[-\Delta H_{(\mathrm{NB} \text { solution })}\right]-0.31
$$

As explained in Section 3, amines may be subject to secondary reactions in DCM. This is the origin of the higher-than-usual uncertainty of the enthalpy value for quinuclidine in DCM. For this reason, the enthalpy value was estimated using Equation (4) as well. This equation was also applied to the enthalpy of solution of $\mathrm{BF}_{3}$ in nitrobenzene, considered as a Lewis base in nitrobenzene solution, leading to an estimation of the enthalpy in DCM.

Table 2 also gives the ab initio calculated enthalpies in DCM and NB solution, and in the gas phase for comparison. Our objective was to reproduce as accurately as possible the absolute enthalpies of $\mathrm{BF}_{3}$ adduct formation in solution, via reactions (2). Previously, we applied the polarized continuum model (PCM) to calculated enthalpy values, using the standard G4 method, for 8 phosphoryl bases [31], and compared with experimentally available data. Although the results were promising, the enthalpies calculated in the two solvents were quite close, with maximum differences of about $2 \mathrm{~kJ} \cdot \mathrm{mol}^{-1}$ for values in the range 27 to $129 \mathrm{~kJ} \cdot \mathrm{mol}^{-1}$. This result was not completely consistent with Equation (4), which indicates that enthalpies in DCM should be approximately $96 \%$ of those in NB. The continuous solvation model for DCM was applied to 12 Lewis bases pertaining to the present study, and the results are given in Table S1 of the Supplementary Materials. The calculated values were almost always too high as compared to the experimental ones. A part of this discrepancy was attributed to a specific solvent effect of DCM, which is known to be a weak hydrogen bond donor (HBD) [50-54]. It may be considered that the interactions of $\mathrm{DCM}$ with the bases and $\mathrm{BF}_{3}$ adducts were primarily dipole/dipole, but the structure of the interacting species (Figure 2) indicates an enhancement by directional hydrogen bonding, through the appropriate orientation of the DCM molecule. 
Table 2. Experimental and calculated enthalpies of adduct formation $\left(-\Delta H, \mathrm{~kJ} \cdot \mathrm{mol}^{-1}\right.$ at $\left.298 \mathrm{~K}\right)$ ) between $\mathrm{BF}_{3}$ and Lewis bases in dichloromethane (DCM) and nitrobenzene (NB) solutions (reaction ( $2 \mathrm{a})$ and $(2 \mathrm{~b})$ ); $\mathrm{kJ} \cdot \mathrm{mol}^{-1}$ ). The signification of uncertainties on experimental enthalpies is discussed in the text. G4*-calculated gas-phase enthalpies are listed in the last column.

\begin{tabular}{|c|c|c|c|c|c|c|c|}
\hline & \multicolumn{3}{|c|}{ Solvent $\mathrm{CH}_{2} \mathrm{Cl}_{2}$ (DCM) } & \multicolumn{3}{|c|}{ Solvent $\mathrm{PhNO}_{2}$ (NB) } & \multirow{2}{*}{$\begin{array}{c}\text { Gas Phase } \\
\text { G4* }\end{array}$} \\
\hline Lewis Base & $\begin{array}{l}\text { Experimental } \\
\text { in } \mathrm{DCM}^{a}\end{array}$ & $\begin{array}{c}\mathrm{G}^{*}+ \\
\text { Discrete } \\
\text { Solvation } \\
\text { Model }^{b}\end{array}$ & $\begin{array}{c}\Delta=\underset{\operatorname{Exp}}{\text { Calc }-} \\
\qquad\end{array}$ & $\begin{array}{l}\text { Experimental } \\
\text { in NB }\end{array}$ & $\begin{array}{c}\mathrm{G}^{*}+ \\
\text { Continuous } \\
\text { Solvation } \\
\text { Model }^{c}\end{array}$ & $\begin{array}{c}\Delta= \\
\text { Calc }- \\
\text { Exp }\end{array}$ & \\
\hline Trimethylamine & $139.5 \pm 1.8$ & 145.7 & 6.2 & & & & $126.4^{e}$ \\
\hline N-Methylpyrrolidine & $139.5 \pm 0.8$ & 143.8 & 4.3 & & & & 125.2 \\
\hline Quinuclidine & $\begin{array}{c}150.01 \pm 3.48 \\
{[153.4 \pm 0.9]^{d}}\end{array}$ & 162.9 & $\begin{array}{l}12.9 \\
{[9.5]}\end{array}$ & $160.5 \pm 0.9$ & 171.2 & 10.7 & 139.1 \\
\hline Pyridine & $128.1 \pm 0.5$ & 126.3 & -1.8 & $137.9 \pm 0.7$ & 137.4 & -0.5 & $100.4^{e}$ \\
\hline Acetonitrile & $60.4 \pm 0.5$ & 60.7 & -0.3 & & & & 32.3 \\
\hline Dimethyl ether & $83.6 \pm 0.2$ & 78.0 & -5.6 & & & & 62.4 \\
\hline Tetrahydrofuran & $90.4 \pm 0.3$ & 96.2 & 5.8 & $93.0 \pm 0.3$ & 103.9 & 10.9 & 74.8 \\
\hline Tetrahydropyran & $85.4 \pm 0.5$ & 81.2 & -4.2 & & & & $69.0^{e}$ \\
\hline Acetone & $76.0 \pm 0.2$ & 74.3 & -1.7 & $78.1 \pm 0.3$ & 82.7 & 4.6 & 54.2 \\
\hline Ethyl acetate & $75.6 \pm 0.3$ & 73.2 & -2.4 & & & & 55.9 \\
\hline$\gamma$-Butyrolactone & $75.1 \pm 1.2$ & 71.7 & -3.4 & & & & 53.1 \\
\hline Dimethyl carbonate & $67.6 \pm 0.4$ & 62.8 & -4.8 & & & & 30.8 \\
\hline Nitrobenzene & {$[35.8 \pm 1.4]^{d, f}$} & 39.3 & [3.5] & $37.7 \pm 1.4^{g}$ & 45.3 & 7.6 & $21.0^{e}$ \\
\hline $\begin{array}{c}\text { Hexamethyl- } \\
\text { phosphoramide } \\
\text { (HMPA) }\end{array}$ & $117.5 \pm 0.5$ & 127.7 & 10.2 & $123.1 \pm 0.5$ & $\begin{array}{c}135.2 \\
(121.9)^{i}\end{array}$ & $\begin{array}{c}12.1 \\
(-1.2)\end{array}$ & $101.3^{h}$ \\
\hline Trimethylphosphine & $97.4 \pm 0.3$ & 97.5 & 0.1 & & & & 66.1 \\
\hline Tetrahydrothiophene & $51.6 \pm 0.2$ & 54.8 & 3.2 & & & & 37.9 \\
\hline
\end{tabular}

${ }^{a}$ Experimental values corresponding to the reaction: $\mathrm{BF}_{3(\text { gas })}+\mathrm{LB}_{(\text {solution })} \rightarrow\left[\mathrm{LB}_{-} \mathrm{BF}_{3}\right]_{(\text {solution) }} \cdot{ }^{b}$ Solvation effects are calculated using a model combining specific interactions (SSM) and a continuum model; see text. ${ }^{c}$ Solvation effects are calculated using a continuum model, including geometry optimization at the B3LYP $/ 6-31+\mathrm{g}(\mathrm{d}, \mathrm{p})$ level of theory. ${ }^{d}$ Secondary value calculated from measurements in NB [25]. The assigned uncertainty corresponds to the repeatability, see text, but additional uncertainties are expected by converting to a value in DCM as solvent. ${ }^{e}$ In these particular cases, the standard G4 yields a higher value than the one obtained with the non-standard G4* procedure; see Table S2. ${ }^{f}$ Value for the Lewis base $\mathrm{PhNO}_{2}$ in $\mathrm{CH}_{2} \mathrm{Cl}_{2}$ solution, estimated using Equation (4), see text. ${ }^{g}$ Value measured for the dissolution of $\mathrm{BF}_{3}$ in pure $\mathrm{PhNO}_{2}$, corresponding to the adduct formation with the Lewis base $\mathrm{PhNO}_{2}$ in $\mathrm{PhNO}_{2}$ solution. ${ }^{h}$ Published value obtained by extrapolation of the G4MP2 results [31]. ${ }^{i}$ Solvation effects do not include geometry optimization. The previously reported value $\left(119.3 \mathrm{~kJ} \cdot \mathrm{mol}^{-1}\right)$ [31] is very close but not strictly equal because the basis set used in the calculation of the solvation effects was different from the one used here.
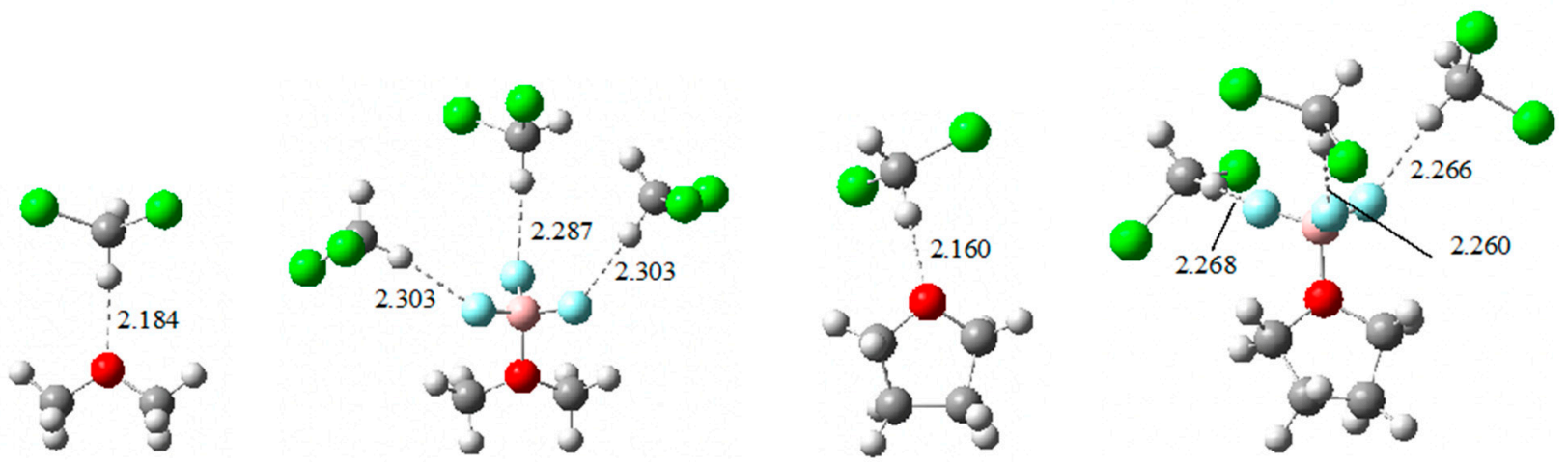

Figure 2. Examples of B3LYP/6.31+G(d,p) optimized structures of hydrogen bonded species which were considered for the specific solvation effect by DCM for dimethyl ether and tetrahydrofuran as suitable example. Before adduct formation, the Lewis base is in interaction with one DCM molecule. Meanwhile, the $\mathrm{BF}_{3}$ adduct is in interaction with three DCM molecules through the three fluorine atoms. H-Bond distances in $\AA$.

It may be argued that halogen bonding may be additionally involved in DCM/Lewis base interaction, but solid phase studies show that hydrogen bonding is dominant for $\mathrm{F}$, $\mathrm{O}, \mathrm{N}, \mathrm{S}$ and P-bases, while it competes with halogen bonding for $\mathrm{Cl}, \mathrm{Br}$, or I-bases [55]. 
Therefore, we can conclude that in our case, H-bonding was the most significant nonspecific solvation in DCM solution.

The enthalpy of $\mathrm{BF}_{3}$ adduct formation may be influenced by specific interactions with DCM acting as HBD molecule in two ways: base/DCM and adduct/DCM. Reactions (2) corresponds to the addition of gaseous $\mathrm{BF}_{3}$ to a Lewis base solution, so $\mathrm{H}$-bonding to the isolated $\mathrm{BF}_{3}$ is not relevant here. The specific solvation of Lewis bases by DCM was suggested by Drago and coworkers [51], and a correction to the $\mathrm{BF}_{3}$ enthalpies for DCM solvation was proposed [52]. Although several modes of $\mathrm{H}$-bonding may be expected for the interaction Lewis base/DCM or $\mathrm{BF}_{3}$ adduct/DCM, we opted for a simple model: one $\mathrm{H}$-bond with the electron lone pair of the Lewis base, and three H-bonds (one on each fluorine of coordinated $\mathrm{BF}_{3}$ ) for the adduct. Figure 2 shows two typical cases of calculated structures of the solutes in reaction (2a) interacting via H-bonding with DCM. In addition to the specific solvation characterized by the Lewis base/DCM and by the adduct/DCM interactions, the PCM model was applied to these H-bonded systems to allow for the non-specific solvation.

Other arrangements with two H-bonds between the basic site and the DCM molecule were higher in energy, and frequently we did not find minima but rather saddle points. Two paradigmatic examples are shown in Figure 3.
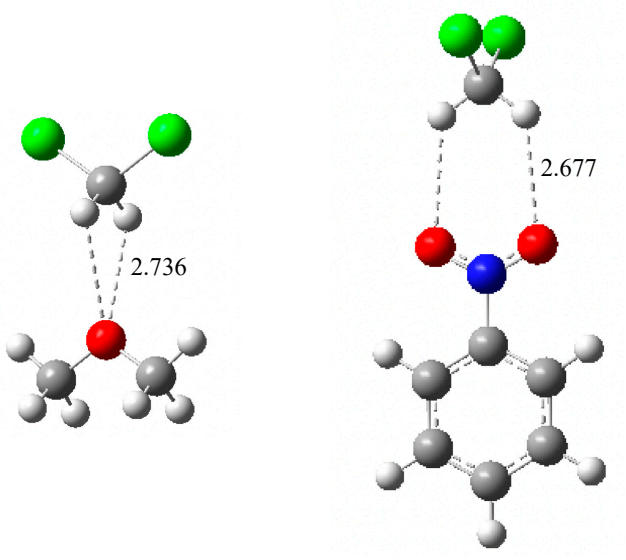

Figure 3. Stable structures for the solvation complexes between dimethyl ether and nitrobenzene with DCM stabilized by two H-bonds. None of them are local minima of the potential energy surface, but rather saddle points with two imaginary frequencies. Hydrogen bond distances in $\AA$.

Solvation by nitrobenzene was considered essentially due to non-specific interaction, and the PCM model was directly applied. In Table 2, we can see that most calculated values at the $\mathrm{G}^{*}$ /specific solvation model (SSM) were within $\pm 6 \mathrm{~kJ} \cdot \mathrm{mol}^{-1}$ (mean unsigned deviation $=4.2 \mathrm{~kJ} \cdot \mathrm{mol}^{-1}$ ) of the experimental values for reaction (2a). There were two exceptions to this fit: quinuclidine and HMPA. Quinuclidine presents some experimental problems for measurements in DCM, explaining the larger-than-usual uncertainty. For this reason, its enthalpy was also measured in NB, and an estimation of the enthalpy in DCM was obtained using Equation (4), showing a better agreement with the calculated values, although still differing by $9.5 \mathrm{~kJ} \cdot \mathrm{mol}^{-1}$. The second exception was HMPA. Our simplified SSM considered only one H-bond on the basic center of the Lewis base, the phosphoryl oxygen atom, but the three nitrogen atoms of the dimethylamino groups are also potential basic sites, although weaker than the phosphoryl. The cluster corresponding to multiple DCM molecules bound to HMPA is not amenable to G4 calculations and the hypothesis of an additional specific solvation on the nitrogen sites of HMPA could not be tested. Overall, the SSM + PCM solvation scheme appeared to perform satisfactorily for reproducing the enthalpies of adduct formation with $\mathrm{BF}_{3}$ for the $\mathrm{N}-, \mathrm{O}-, \mathrm{P}$ - and S-bases studied.

The success of PCM solvation applied to the measurements conducted in nitrobenzene as solvent was mitigated. The calculated $-\Delta H$ values for the six cases in Table 2 were almost all too large, with disagreements with experimental enthalpies up to $12 \mathrm{~kJ} \cdot \mathrm{mol}^{-1}$. 
It should be noted, as far as the calculations are concerned, that our theoretical treatment included geometry optimization of the complex when solvent effects were accounted for. Curiously, for HPMA, these values were in worse agreement with the experimental ones than those obtained when no geometry optimization of the complex was carried out. Provisionally, we assigned this observation to the neglect of the potential solvation of the $\mathrm{NMe}_{2}$ groups of HMPA in the SSM.

We wish to point out that the high computational level required to reproduce $\Delta \mathrm{BBF}_{3}$ values is not attainable for $\mathrm{DN}$ (i.e., enthalpies of adduct formation with $\mathrm{SbCl}_{5}$ in solution). This is a further advantage of using $\Delta \mathrm{HBF}_{3}$ as a Lewis basicity scale, as it widens the possibilities of evaluating this type of basicity for species other than those already experimentally characterized by calorimetry [5].

Finally, it is worth mentioning that, as illustrated in Figure 4, there was a rather good linear correlation between the experimental enthalpies $\triangle \mathrm{HBF}_{3}$ in $\mathrm{DCM}$ solution and the $\mathrm{G} 4^{*}$ calculated values obtained using the discrete solvation model (SSM). This linear correlation obeys the equation:

$$
-\Delta \mathrm{HBF}_{3 \mathrm{calc}}=1.078\left(-\Delta \mathrm{HBF}_{3 \exp \cdot \mathrm{DCM}}\right)-5.900 ; R^{2}=0.985
$$

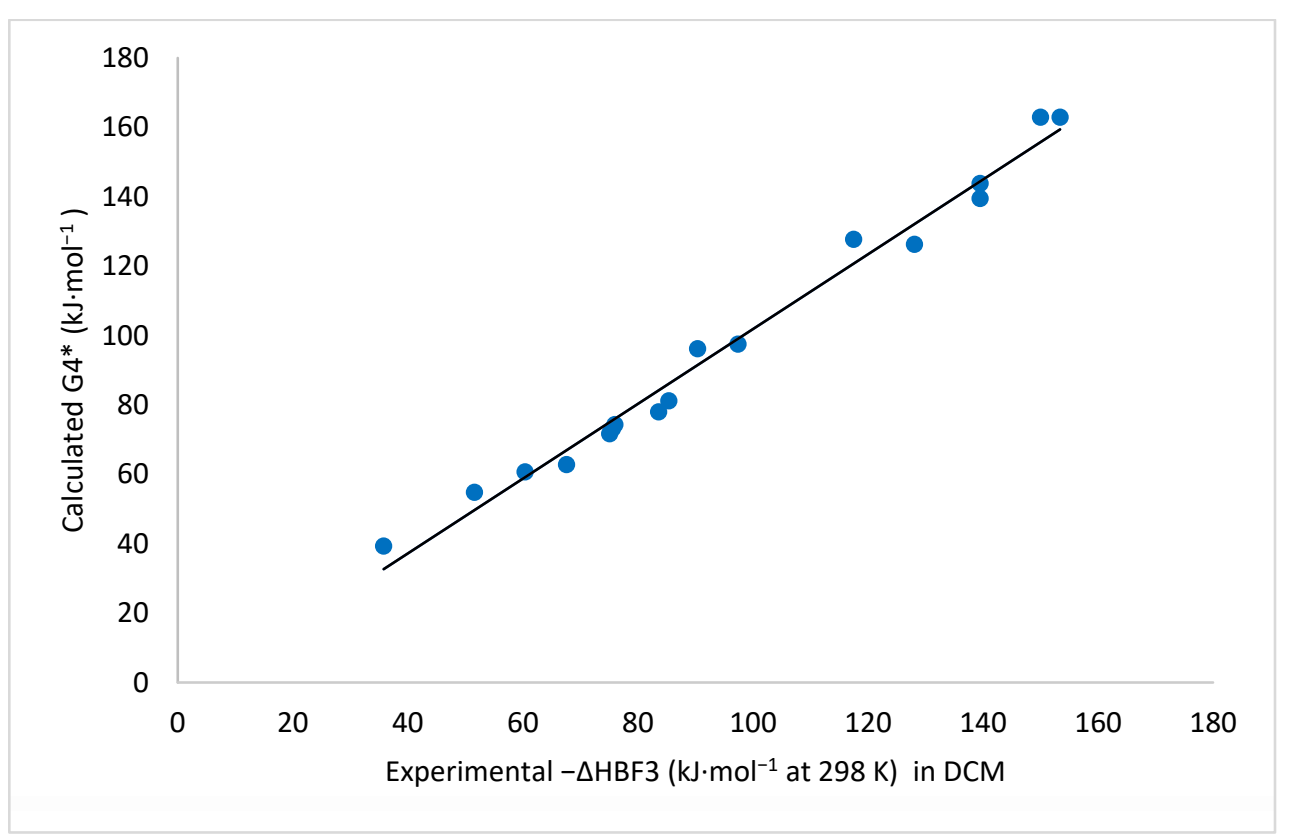

Figure 4. Linear correlation between the experimental enthalpies of adduct formation $\left(-\triangle \mathrm{HBF}_{3 \exp \cdot \mathrm{DCM})}\right)$ and the $\mathrm{G} 4^{*}$ calculated values obtained using the discrete solvation model.

\section{Materials and Methods}

\subsection{Calorimetric Method}

We succinctly recall the essentials of the calorimetric method utilized for our enthalpy measurements [26]. The calorimeter was a Tian-Calvet differential microcalorimeter, with two $17 \mathrm{~mm}$ diameter cells. The measuring and reference cells were made of borosilicate glass. All measurements were taken at $25.0 \pm 0.1^{\circ} \mathrm{C}$, under ambient atmospheric pressure. The system was calibrated using the Joule effect, giving uncertainties on the calorimeter calibration constant much less than $0.1 \%$ (short time precision at the $95 \%$ confidence level for a series of more than 10 measurements), and approximately $0.5 \%$ for long-term accuracy (drift of the constant over 5 years). The $\mathrm{BF}_{3}$ quantity injected into the Lewis base solution was measured by a mercury manometer (PVT measurements) in a constant temperature room at $20.0 \pm 0.1^{\circ} \mathrm{C}$. The repeatability of the enthalpies reported in Table 2 (usual range $0.5-1 \%$ for approximately 10 consecutive measurements on the same solution) was largely due to errors in the $\mathrm{BF}_{3}$ measurements. The long-term reproducibility (several years) of 
the calibration constant was better than $0.5 \%$ when considering the drift of the calibration constant. Systematic errors also arose from measurements of gas quantities, which were evaluated as approximately $0.2 \%$ [26]. Our calorimetric measurements gave absolute enthalpies of reaction measured consistently using the same protocol. Comparing our data to those measured by H. C. Brown and coworkers for five Lewis bases in NB solution, using a different calorimetric procedure, we observed fair to excellent agreement [25], showing that systematic errors on our enthalpies were less than $1 \%$.

In some cases, we had to consider larger than usual errors in the heat effect, because of secondary reactions. The amines tend to react with methylene chloride to very different degrees $[51,56]$. For trimethylamine and $N$-methylpyrrolidine, we did not observe significant DCM/amine or DCM/adduct reactions, but quinuclidine displayed this problem. This DCM/quinuclidine concentration-dependent reaction was previously observed by Drago et al. [51]. The larger uncertainty on the enthalpy of adduct formation in DCM for this compound was imputed to such problem.

\subsection{Computational}

The G4* approach used in our calculations is a slight modification of the G4 ab initio method [57]. The G4 theory is a composite formalism based on the use of MøllerPlesset perturbation theory up to fourth order and CCSD(T) coupled cluster theory to accurately describe electron correlation effects. The method includes a final correction for the Hartree-Fock limit, evaluated using an extrapolation procedure and quadruplezeta and quintuple-zeta basis sets. It must be mentioned, however, that in this study we introduced a slight modification as far as the optimized geometries are concerned. Indeed, since in our case we were dealing with rather weak interactions which usually required the use of diffuse functions which are not included in the standard G4 formalism, which uses B3LYP/6-31G(2df,p) optimized geometries, we decided to use B3LYP/aug-cc-pVTZ optimized geometries (see Table S4 of the Supplementary Materials) instead. These slightly modified G4 calculations are named as G4* elsewhere.

To analyze the bonding characteristics of some of the complexes under investigation chosen as suitable illustrations, we used two different approaches, namely the atoms in molecules (AIM) method [58] and the Natural Bond Orbital (NBO) approach [59].

The AIM method permits the location of the so-called bond critical points (BCPs) and calculation of the corresponding electron density, whose value at the BCPs is a good measure of the strength of the linkage as well as providing information about its covalent character, through the values and signs of the Laplacian and energy density. The NBO method provides, through an appropriate molecular orbital localization scheme, a description of the systems in terms of a Lewis type representation. When dealing with intermolecular interactions, this approach is very well suited to estimating the relative strength of the interaction between the groups involved.

To account for solvation effects, we used semi-continuum or cluster-continuum approaches [60]. Often used in the context of solvation of ions by water, these approaches are supposed to complete the electrostatic description of the polarized continuum model (PCM) developed by Tomasi et al. [61]. In the model, the continuum approaches are used on clusters in which the molecule and its adduct with $\mathrm{BF}_{3}$ are specifically solvated by one and three molecules of DCM, respectively. This notably increases the size of the systems to be investigated, and therefore these calculations to account for the solvation stabilization effects were carried out at the B3LYP/6-31+G(d,p) level of theory.

\section{Conclusions}

The experimental enthalpies of adduct formation between neutral Lewis bases and boron trifluoride measured in dichloromethane are available for about 350 molecules [5]. One of our objectives was the reproduction of absolute enthalpy values using state-of-theart ab initio approaches. A previous work on a series of phosphoryl compounds using G4 calculations and a continuous solvation model was rather successful, but application to 
the various bases included in the present work led us to conclude that the solvation model should be refined. An improved $\mathrm{G}^{*}$ combined with a solvation model including specific hydrogen bonding to the Lewis base and the $\mathrm{BF}_{3}$ adduct, completed by a continuous solvation model (PCM), was more satisfactory for the reproduction of the experimental enthalpies in DCM.

Comparison of $\mathrm{BF}_{3}$ enthalpies measured and calculated in the gas-phase and in DCM solution showed that the solvent effect was sizeable. The use of DCM for reaction (2a), similarly to the use of DCE (1,2-dichloroethane) for reaction (1), was dictated by solubility problems, mainly for the $\mathrm{BF}_{3}$ adducts, which are poorly soluble in low polarity solvents such as tetrachloromethane and alkanes.

Solvation is an important component of Lewis basicity measurements. A recent computational study focused on Gibbs energies of adduct formation between antimony pentahalides and group 13 Lewis acids (among them $\mathrm{SbCl}_{5}$ and $\mathrm{BF}_{3}$ ), and the Lewis bases acetonitrile and pyridine, examined the solvent effect on the basis of a continuous dielectric model. The authors concluded that electrostatic, dispersion and electron-repulsive solutesolvent interactions were essential for the prediction of solvation effects [62], while the solvents selected for the study did not include possible hydrogen bond-donor solvents. It is worth mentioning that $\mathrm{G} 4 / \mathrm{G} 4^{*}$ calculations are not currently possible for antimony pentahalide adducts, in particular for estimating $\mathrm{DN}$ via reaction (1).

Our hybrid discrete-continuum solvation model approach appeared to be efficient for the selected Lewis bases. Most experimental $\Delta \mathrm{HBF}_{3}$ were reproduced within $\pm 6 \mathrm{~kJ} \mathrm{~mol}^{-1}$, opening the way to the theoretical evaluation of Lewis basicity, as defined by reaction (2a), in particular for molecules not experimentally characterized. At the cost of timeconsuming and expensive computations, more sophisticated DCM/Lewis bases and $\mathrm{DCM} / \mathrm{BF}_{3}$ adducts may be devised, but for more widespread applicability, it is probably advisable to search for less expensive methods.

The importance of solvent effects on Lewis basicity points out the necessity of distinguishing between the Lewis basicity defined by reactions (1) and (2) and "solvent basicity". Solvent basicity is often an ill-defined property, considering only the experimental or computed thermochemistry of reactions (1), (2a), (2b) and (3), and ignoring the "bulk effect", i.e., the variable solvation of each solvent [35]. Further experimental and computational studies are planned on the Lewis basicity of solvents as opposed to solutes, i.e., the enthalpy of solution of $\mathrm{BF}_{3}$ in bulk liquids.

Supplementary Materials: The following are available online. Table S1. Calculated solvation effects on the enthalpies of $\mathrm{BF}_{3}$ adduct formation; Table S2. Comparison of calculated gas-phase enthalpies: G4* vs. standard G4; Table S3. Comparison of experimental gas-phase PAs with G4-calculated values; Table S4. Optimized structures of the adducts formed between boron trifluoride and Lewis bases included in this study.

Author Contributions: Conceptualization, methodology, experimental measurements, writing, editing, J.-F.G. and P.-C.M. Conceptualization, calculations, writing, funding acquisition, M.Y. and O.M. All authors have read and agreed to the published version of the manuscript.

Funding: This work was carried out with financial support from the projects PGC2018-094644-B-C21 and PID2019-110091GB-I00 (MICINN) of the Ministerio de Ciencia, Innovación y Universidades of Spain.

Institutional Review Board Statement: Not applicable.

Informed Consent Statement: Not applicable.

Data Availability Statement: Not applicable.

Acknowledgments: JFG and PCM acknowledge the continuous support from the Institut de Chimie de Nice, UMR CNRS 7272. MY and OM thank the Centro de Computación Científica of the UAM (CCC-UAM) for the generous allocation of computer time and for their continued technical support.

Conflicts of Interest: The authors declare no conflict of interest. 
Sample Availability: Samples of the compounds not are available from the authors.

\section{References}

1. Gur'yanova, E.N.; Gol'dshtein, I.P.; Romm, I.P. Donor-Acceptor Bond; Wiley: New York, NY, USA, 1975.

2. Gutmann, V. The Donor-Acceptor Approach to Molecular Interactions; Plenum: New York, NY, USA, 1978.

3. Jensen, W.B. The Lewis Acid-Base Concepts: An Overview; Wiley: New York, NY, USA, 1980.

4. $\quad$ Finston, H.L.; Rychtman, A.C. New View of Current Acid-Base Theories; Wiley: New York, NY, USA, 1982.

5. Laurence, C.; Gal, J.-F. Lewis Basicity and Affinity Scales: Data and Measurement; Wiley: New York, NY, USA, 2010.

6. Laurence, C.; Graton, J.; Gal, J.-F. An Overview of Lewis Basicity and Affinity Scales. J. Chem. Educ. 2011, 88, 1651-1657. [CrossRef]

7. Laurence, C.; Graton, J.; Berthelot, M.; Besseau, F.; Le Questel, J.-Y.; Luçon, M.; Ouvrard, C.; Planchat, A.; Renault, E. An Enthalpic Scale of Hydrogen-Bond Basicity. 4. Carbon $\pi$ Bases, Oxygen Bases, and Miscellaneous Second-Row, Third-Row, and Fourth-Row Bases and a Survey of the 4-Fluorophenol Affinity Scale. J. Org. Chem. 2010, 75, 4105-4123. [CrossRef] [PubMed]

8. Kone, M.; Illien, B.; Laurence, C.; Graton, J. Can Quantum-Mechanical Calculations Yield Reasonable Estimates of HydrogenBonding Acceptor Strength? The Case of Hydrogen-Bonded Complexes of Methanol. J. Phys. Chem. A 2011, 115, 13975-13985. [CrossRef]

9. Laurence, C.; Graton, J.; Berthelot, M.; El Ghomari, M.J. The Diiodine Basicity Scale: Toward a General Halogen-Bond Basicity Scale. Chem. Eur. J. 2011, 17, 10431-10444. [CrossRef] [PubMed]

10. Maria, P.-C.; Gal, J.-F.; de Franceschi, J.; Fargin, E. Chemometrics of the Solvent Basicity: Multivariate Analysis of the Basicity Scales Relevant to Nonprotogenic Solvents. J. Am. Chem. Soc. 1987, 109, 483-492. [CrossRef]

11. Pearson, R.G. Hard and soft acids and bases-The evolution of a chemical concept. Coord. Chem. Rev. 1990, 100, 403-425. [CrossRef]

12. Drago, R.S. Applications of Electrostatic-Covalent Models in Chemistry; Surfside: Gainesville, FL, USA, 1994.

13. Gutmann, V.; Mayer, U. Donorstärken in 1,2-Dichloräthan, 3. Mitt. (Donor strengths in 1,2-dichloroethane. Part 3). Monatsh. Chem. 1967, 98, 294-297. [CrossRef]

14. Gutmann, V. Coordination Chemistry in Non-Aqueous Solutions; Springer: Vienna, Austria, 1968.

15. Marcus, Y. The Effectivity of Solvents as Electron Pair Donors. J. Solut. Chem. 1984, 13, 599-624. [CrossRef]

16. Hong, M.; Chen, J.; Chen, E.Y.-X. Polymerization of Polar Monomers Mediated by Main-Group Lewis Acid-Base Pairs. Chem. Rev. 2018, 118, 10551-10616. [CrossRef] [PubMed]

17. Hamill, J.C., Jr.; Schwartz, J.; Loo, Y.-L. Influence of Solvent Coordination on Hybrid Organic-Inorganic Perovskite Formation. ACS Energy Lett. 2018, 3, 92-97. [CrossRef]

18. Zhang, L.; Li, J.; Huang, Y.; Zhu, D.; Wang, H. Synergetic Effect of Ethyl Methyl Carbonate and Trimethyl Phosphate on BF ${ }_{4}^{-}$ Intercalation into a Graphite Electrode. Langmuir 2019, 35, 3972-3979. [CrossRef] [PubMed]

19. Clancy, P. Balancing Multiple Goals and Making It Work for Materials Research. ACS Cent. Sci. 2020, 6, 464-466. [CrossRef] [PubMed]

20. Gnida, P.; Libera, M.; Pajakk, A.; Schab-Balcerzak, E. Examination of the Effect of Selected Factors on the Photovoltaic Response of Dye-Sensitized Solar Cells. Energy Fuels 2020, 34, 14344-14355. [CrossRef]

21. Baek, M.; Shin, H.; Char, K.; Choi, J.W. New High Donor Electrolyte for Lithium-Sulfur Batteries. Adv. Mater. 2020, $32,2005022$. [CrossRef]

22. Romiluyi, O.; Eatmon, Y.; Ni, R.; Rand, B.P.; Clancy, P. The efficacy of Lewis affinity scale metrics to represent solvent interactions with reagent salts in all-inorganic metal halide perovskite solutions. J. Mater. Chem. A 2021, 9, 13087-13099. [CrossRef]

23. Lee, D.-K.; Lim, K.-S.; Leeb, J.-W.; Park, N.-G. Scalable perovskite coating via anti-solvent-free Lewis acid-base adduct engineering for efficient perovskite solar modules. J. Mater. Chem. A 2021, 9, 3018-3028. [CrossRef]

24. Gupta, A.; Bhargav, A.; Manthiram, A. Evoking High-Donor-Number-Assisted and Organosulfur-Mediated Conversion in Lithium-Sulfur Batteries. ACS Energy Lett. 2021, 6, 224-231. [CrossRef]

25. Maria, P.-C.; Gal, J.-F. A Lewis basicity scale for nonprotogenic solvents: Enthalpies of complex formation with boron trifluoride in dichloromethane. J. Phys. Chem. 1985, 89, 1296-1304. [CrossRef]

26. Maria, P.-C.; Gal, J.-F.; Elégant, L.; Azzaro, M. A microcalorimetric method for the measurement of the enthalpies of solution of gases in liquids. Thermochim. Acta 1987, 115, 67-81. [CrossRef]

27. Hamill, J.C., Jr.; Romiluyi, O.; Thomas, S.A.; Cetola, J.; Schwartz, J.; Toney, M.F.; Clancy, P.; Loo, Y.-L. Sulfur-Donor Solvents Strongly Coordinate $\mathrm{Pb}^{2+}$ in Hybrid Organic-Inorganic Perovskite Precursor Solutions. J. Phys. Chem. C 2020, 124, 14496-14502. [CrossRef]

28. Smiatek, J. Enthalpic contributions to solvent-solute and solvent-ion interactions: Electronic perturbation as key to the understanding of molecular attraction. J. Chem. Phys. 2019, 150, 174112. [CrossRef] [PubMed]

29. Mayer, R.J.; Hampel, N.; Ofial, A.R. Lewis Acidic Boranes, Lewis Bases, and Equilibrium Constants: A Reliable Scaffold for a Quantitative Lewis Acidity/Basicity Scale. Chem. Eur. J. 2021, 27, 4070-4080. [CrossRef] [PubMed]

30. Miranda-Quintana, R.A.; Smiatek, J. Calculation of donor numbers: Computational estimates for the Lewis basicity of solvents. J. Mol. Liq. 2021, 322, 114506. [CrossRef] 
31. Gal, J.-F.; Maria, P.-C.; Yáñez, M.; Mó, O. On the Lewis basicity of phosphoramides: A critical examination of their Donor Number through the comparison of enthalpies of adduct formation with $\mathrm{SbCl}_{5}$ and $\mathrm{BF}_{3}$. Chem. Phys. Chem. 2019, 20, 2566-2576. [CrossRef] [PubMed]

32. Jaworski, J.S.; Bankiewicz, B.; Krygowski, T.M.; Palusiak, M.; Stasyuk, O.A.; Szatylowicz, H. Interactions of polar hydrogen bond donor solvents with ions: A theoretical study. Struct. Chem. 2016, 27, 1279-1289. [CrossRef]

33. Sorenson, B.A.; Hong, S.S.; Herbol, H.C.; Clancy, P. How well do implicit solvation models represent intermolecular binding energies in organic-inorganic solutions? Comput. Mat. Sci. 2019, 170, 109138. [CrossRef]

34. Herbol, H.C.; Hu, W.; Frazier, P.; Clancy, P.; Poloczek, M. Efficient search of compositional space for hybrid organic-inorganic perovskites via Bayesian optimization. NPJ Comput. Mat. 2018, 4, 51. [CrossRef]

35. Gal, J.-F.; Maria, P.-C. Can the Lewis Basicity of an Isolated Solvent Molecule be Used for Characterizing Solvent Effects? Curr. Anal. Chem. 2021, 17, 328-338. [CrossRef]

36. Shepp, A.; Bauer, S.H. Computation of Entropy Increments in Gaseous Bimolecular Associations. I. Donor-Acceptor Reactions. J. Am. Chem. Soc. 1954, 76, 265-270. [CrossRef]

37. Bauer, S.H.; McCoy, R.E. Energetics of the Boranes. I. The Heats of Reaction of Diborane with the Methylamines, and of Tetramethyldiborane with Trimethylamine; the Dissociation Energy of Diborane. J. Am. Chem. Soc. 1956, 76, $2061-2065$.

38. Bauer, S.H.; McCoy, R.E. Energetics of the Boranes. III. The Enthalpy and Heat Capacity of Trimethylamine-Trifluoroborane as Determined by the Drop Method. J. Phys. Chem. 1956, 60, 1529-1532. [CrossRef]

39. McLaughin, D.E.; Tamres, M. The boron trifluoride addition compounds of dimethyl ether and diethyl ether. J. Am. Chem. Soc. 1960, 82, 5618-5621. [CrossRef]

40. McLaughin, D.E.; Tamres, M.; Searles, S., Jr. The addition compounds of cyclic ethers with boron trifluoride. J. Am. Chem. Soc. 1960, 82, 5621-5625. [CrossRef]

41. Sacks, L.J.; Drago, S.R.; Eyman, D.P. Gas-phase enthalpies of adduct formation: Dimethylamine-chloroform and ethyl acetateboron trifluoride. Inorg. Chem. 1968, 7, 1484-1488. [CrossRef]

42. Brown, H.C. Chemical Effects of Steric Strains. J. Chem. Soc. 1956, 1248-1268. [CrossRef]

43. Morris, H.L.; Tamres, M.; Searles, S. The addition compounds of some phosphines with boron trifluoride, borane, and trimethylboron. Inorg. Chem. 1966, 5, 2156-2160. [CrossRef]

44. Morris, H.L.; Kulevsky, I.N.; Tamres, M.; Searles, S., Jr. The addition compounds of some sulfides with boron trifluoride and with boron trichloride. Inorg. Chem. 1966, 5, 124-130. [CrossRef]

45. Davydova, E.I.; Sevastianova, T.N.; Suvorov, A.V.; Timoshkin, A.Y. Molecular complexes formed by halides of group 4,5,13-15 elements and the thermodynamic characteristics of their vaporization and dissociation found by the static tensimetric method. Coord. Chem. Rev. 2010, 254, 2031-2077. [CrossRef]

46. Chickos, J.S.; Acree, W.E. Enthalpies of sublimation of organic and organometallic compounds. 1910-2001. J. Phys. Chem. Ref. Data 2002, 31, 537-698. [CrossRef]

47. NIST Chemistry WebBook. NIST Standard Reference Database No. 69; Linstrom, P.J., Mallard, W.G., Eds.; National Institute of Standards and Technology: Gaithersburg, MD, USA, 2014. Available online: http:/ / webbook.nist.gov/chemistry (accessed on 14 September 2021).

48. Fletcher, E.A. A Study of the Steric Consequences of Planar Boron-The Base Strengths of the Methylphosphines. Ph.D. Thesis, Purdue University, West Lafayette, IN, USA, 1952.

49. Rauk, A.; Hunt, I.R.; Keay, B.A. Lewis acidity and basicity: An ab initio study of proton and $\mathrm{BF}_{3}$ affinities of oxygen-containing organic compound. J. Org. Chem. 1994, 59, 6808-6916. [CrossRef]

50. Allerhand, A.; von Schleyer, P.R. A Survey of C-H Groups as Proton Donors in Hydrogen Bonding. J. Am. Chem. Soc. 1963, 85, 1715-1723. [CrossRef]

51. Drago, R.S.; Nusz, J.A.; Courtright, R.C. Solvation Contributions to Enthalpies Measured in Methylene Chloride. J. Am. Chem. Soc. 1974, 96, 2082-2086. [CrossRef]

52. Drago, R.S.; Dadmun, A.P.; Vogel, G.C. Addition of New Donors to the E and C Model. Inorg. Chem. 1993, 32, 2473-2479. [CrossRef]

53. Cerón-Carrasco, J.P.; Jacquemin, D.; Laurence, C.; Planchat, A.; Reichardt, C.; Sraïdi, K. Determination of a solvent hydrogen-bond acidity scale by means of the solvatochromism of pyridinium-N-phenolate betaine dye 30 and PCM-TD-DFT calculations. J. Phys. Chem. B 2014, 118, 4605-4614. [CrossRef]

54. Rakipov, I.T.; Petrov, A.A.; Akhmadiyarov, A.A.; Khachatrian, A.A.; Mukhametzyanov, T.A.; Solomonov, B.N. Thermochemistry of Solution, Solvation, and Hydrogen Bonding of Cyclic Amides in Proton Acceptor and Donor Solvents. Amide Cycle Size Effect. Molecules 2021, 26, 1411. [CrossRef] [PubMed]

55. Mooibroek, T.J.; Gamez, P. Halogen bonding versus hydrogen bonding: What does the Cambridge Database reveal? Cryst. Eng. Comm. 2013, 15, 4565-4570. [CrossRef]

56. Mills, J.E.; Maryanoff, C.A.; Cosgrove, R.M.; Scott, L.; McComsey, D.F. The reactions of amines with methylene chloride. A brief review. Org. Prep. Proc. Int. 1984, 16, 97-114. [CrossRef]

57. Curtiss, L.A.; Redfern, P.C.; Raghavachari, K. Gaussian-4 theory. J. Chem. Phys. 2007, 126, 84108. [CrossRef]

58. Bader, R.F.W. Atoms in Molecules. A Quantum Theory; Clarendon Press: Oxford, UK, 1990. 
59. Reed, A.E.; Curtiss, L.A.; Weinhold, F. Intermolecular interactions from a natural bond orbital, donor-acceptor viewpoint. Chem. Rev. 1988, 88, 899-926. [CrossRef]

60. Herbert, J.M. Dielectric continuum methods for quantum chemistry. Wiley Interdiscip. Rev. Comput. Mol. Sci. 2021, 11, e1519. [CrossRef]

61. Tomasi, J.; Mennucci, B.; Cammi, R. Quantum mechanical continuum solvation models. Chem. Rev. 2005, 105, 2999-3093. [CrossRef] [PubMed]

62. Pomogaeva, A.V.; Timoshkin, A.Y. Influence of the solvent on the Lewis acidity of antimony pentahalides and group Lewis acids toward acetonitrile and pyridine. J. Comput. Chem. 2021, 42, 1792-1802. [CrossRef] [PubMed] 